\title{
In memoriam: Professor Yukio Nose (1926-2019)
}

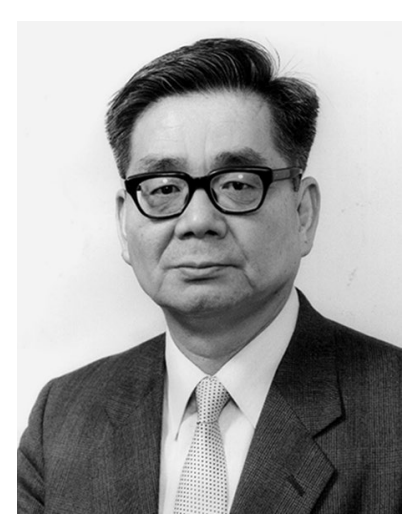

Professor Yukio Nose, an Honorary Member of the Japanese Society of Fisheries Science and Professor Emeritus of the University of Tokyo, passed away on 16 April 2019 at the age of 92.

Professor Nose was born in Osaka on 18 August 1926. He graduated from the Department of Fisheries, the University of Tokyo, in 1950 and was appointed as an assistant professor of the department in May that year. After that, he was promoted to a lecturer in 1963, associate professor in 1965, and professor in 1969. He concurrently served as the Director of the Fisheries Laboratory attached to the Faculty of Agriculture, the University of Tokyo (1975-1978), and the Director of the University Museum, the University of Tokyo (1985-1987), retiring from the university in 1987.

Professor Nose was consistently engaged in research on the biology of fish resources. He was well known for his rigorous research based on thorough planning, extensive knowledge and statistical insights, as well as for his longterm continuous research. He achieved a high level of performance in basic research and made significant contributions to society through the application of his research. Professor Nose focused on the following areas of research:

1. Fish stock estimation by mark and recapture. He reviewed the Petersen method, which estimates fish stock abundance by mark and recapture, and devised a method to eliminate bias in the estimated values due to continuous mark depletion. He also proposed methods for estimating the stock abundance when there is recruitment, and for estimating natural mortality coefficients.
Furthermore, he systematized the mark and recapture analysis theory, which was applied to various fish species as a standard method for stock estimation and contributed immensely to the research of fishery resources.

2. Characteristics of salmon stocks. A long-term survey of the salmon Oncorhynchus keta in rivers around the Tohoku region revealed the characteristics of the local stock in each river, such as upstream ecology and breeding traits. The results led to the proposal of registering local salmon stocks and provided an important basis for transplanting and breeding.

3. Age and growth of fish species. He made numerous achievements in research on age determination and growth of fish species. This revealed an appropriate method for determining the age of various fish species around Japan and laid the foundation for research related to the age, growth and other characteristics of fishery resources.

In addition to serving as a member of the Board of Directors of the Japanese Society of Fisheries Science for many years, he served as Vice President of the Society from 1982 to 1983 and again from 1988 to 1989 . In 1989, he was honored with the Japanese Society of Fisheries Science Award of Merit for his "Research on Fish Resource Biology".

He served on many government-affiliated committees such as the Expert Committee for Atomic Energy Commission, Expert Committee for Central Council for Environmental Pollution Control, Coastal Fisheries Promotion Council Committee, Natural Environment Conservation Council, Expert Committee for University Establishment, and Environmental Review Advisory.

Professor Yukio Nose will be remembered by his students and all who knew him for his warm personality, Osaka dialect, profound insights, and academic discipline. We express our condolences to his loved ones at this difficult time.

Makoto Shimizu

Professor Emeritus, the University of Tokyo

Publisher's Note Springer Nature remains neutral with regard to jurisdictional claims in published maps and institutional affiliations. 